\title{
Cannabinoid receptor type 1 mediates high-fat diet-induced insulin resistance by increasing forkhead box 01 activity in a mouse model of obesity
}

\author{
CHIN-CHANG CHEN ${ }^{1}$, TZUNG-YAN LEE ${ }^{2}$, CHING-FAI KWOK ${ }^{3}$, YUNG-PEI HSU ${ }^{4}$, \\ KUANG-CHUNG SHIH ${ }^{3}$, YAN-JIE LIN ${ }^{1}$ and LOW-TONE HO $\mathrm{HO}^{1,3-5}$ \\ ${ }^{1}$ Institute of Physiology, National Yang-Ming University, Taipei; ${ }^{2}$ Graduate Institute of Traditional Chinese Medicine, \\ Chang Gung University, Tao-Yuan; ${ }^{3}$ Division of Endocrinology and Metabolism, Department of Medicine, \\ ${ }^{4}$ Department of Medical Research, Taipei Veterans General Hospital; ${ }^{5}$ School of Medicine, \\ National Yang-Ming University, Taipei, Taiwan, R.O.C.
}

Received March 18, 2015; Accepted December 9, 2015

DOI: $10.3892 /$ ijmm.2016.2475

\begin{abstract}
Hepatic glucose production is promoted by forkhead box $\mathrm{O} 1$ (FoxO1) under conditions of insulin resistance. The overactivity of cannabinoid receptor type 1 (CB1R) partly causes increased liver fat deposits and metabolic dysfunction in obese rodents by decreasing mitochondrial function. The aim of the present study was to investigate the role of FoxO1 in CB1R-mediated insulin resistance through the dysregulation of mitochondrial function in the livers of mice with high-fat diet (HFD)-induced obesity. For this purpose, male C57BL/6 mice were randomly assigned to groups and either fed a standard diet (STD), a HFD, or a HFD with 1-week treatment of the CB1R inverse agonist, AM251, at 1 or $5 \mathrm{mg} / \mathrm{kg}$. For in vitro experiments, AML12 hepatocytes were incubated with FoxO1 siRNA prior to challenge with arachidonyl2'-chloroethylamide (ACEA) or a high concentration of free fatty acids (HFFA). Plasma parameters were analyzed using colorimetric methods. Liver histopathology and hepatic status markers were examined. The HFD-fed mice exhibited an increase in CB1R levels in the liver. Moreover, in response to increased hepatic oxidative stress, the HFD-fed mice also displayed hepatic mitochondrial dysfunction, as indicated by the decreased mRNA levels of carnitine palmitoyltransferase-1 (CPT-1), mitochondrial transcription factor A (TFAM), nuclear respiratory factor-1 (NRF-1) and citrate synthase. On the contrary, these effects in the HFD-fed mice were reversed by treatment with $5 \mathrm{mg} / \mathrm{kg}$ AM251. The administration of AM251 suppressed the induction of FoxO1, phosphoenolpyruvate
\end{abstract}

Correspondence to: Professor Low-Tone Ho, Department of Medical Research, Taipei Veterans General Hospital, 201, Section 2, Shipai Road, Beitou, Taipei 11217, Taiwan, R.O.C.

E-mail: 1tho@vghtpe.gov.tw

Key words: cannabinoid receptor type 1, forkhead box O1, insulin resistance, high fat diet, mitochondrial dysfunction, hepatic oxidative stress carboxykinase (PEPCK) and glucose 6-phosphatase (G6Pase) expression in the livers of the mice fed a HFD by enhancing the phosphorylation of insulin signaling cascades thus, further lowering the high level of the homeostatic model assessment of insulin resistance (HOMA-IR) index. In our in vitro experiments, transfection with FoxO1 siRNA prevented the HFFA- and ACEA-induced decrease in the gene expression of mitochondrial biogenesis-related factors, and abrogated the HFFA- and ACEA-induced increase in PEPCK and G6Pase expression. Taken together, our findings suggest that the anti-insulin resistance effect of AM251, which leads to an improvement of mitochondrial function in hepatic steatosis, is mediated through FoxO1.

\section{Introduction}

Obesity is characterized by increased lipid storage in visceral adipose tissue, and is associated with ectopic lipid deposition in non-adipose tissue, such as the liver and skeletal muscle. Non-alcoholic fatty liver disease (NAFLD) has emerged as a growing public health concern worldwide (1) and encompasses a spectrum of pathological conditions, ranging from simple steatosis to non-alcoholic steatohepatitis (NASH), resulting from oxidative stress, lipid peroxidation and increased cytokine production (2). In NASH, lipids that accumulate in the liver are derived from circulating fatty acids (FAs) which occurs due to the insulin resistance-associated dysregulation of peripheral lipolysis, and de novo lipogenesis (DNL). During NAFLD, increased mitochondrial FA oxidation plays a critical role in producing additional adenosine triphosphate (ATP) needed for DNL and gluconeogenesis (3). This adaption induces an increase in reactive oxygen species (ROS) production, and further impairs energy output, which results from a reduction in the mitochondrial respiratory chain and promotes lipid peroxidation and mitochondrial DNA (mtDNA) damage (4-7). A progressive loss of mitochondrial function in conjunction with the transition from insulin resistance to type 2 diabetes (T2D) likely contributes to the progression of NAFLD (8). Moreover, mitochondrial glutathione (GSH) depletion has been reported 
in models of alcoholic steatohepatitis/NASH (9). Accordingly, NASH has been described as a mitochondrial disease (10).

Forkhead box O1 (FoxO1) is a critical mediator of cellular stress response and has been implicated in numerous nutrient-regulated processes (11); for example, FoxO1 plays an important role in controlling the expression of genes involved in gluconeogenesis in the liver $(12,13)$. In this regard, transgenic mice expressing a constitutively active FoxO1 allele exhibit insulin resistance and hepatic steatosis (14), whereas the antisense oligonucleotide-mediated targeted reduction of FoxO1 in the liver or adipose tissue has been shown to improve glucose tolerance and peripheral insulin function in mice with diet-induced obesity (DIO) $(15,16)$. As regards individuals with obesity and T2D, studies have documented the reduced ability of insulin to suppress glucose production and gluconeogenesis, and this effect was principally driven by the increased activity of phosphoenolpyruvate carboxykinase (PEPCK) and glucose 6-phosphatase (G6Pase) (17,18). Thus, the disruption FoxO1 activity has been demonstrated to improve hepatic and peripheral insulin sensitivity, and subsequently reduce fasting glucose levels in obese or diabetic mice $(13,19)$. In addition, FoxO1 mediates the effects of insulin on triglyceride (TG) metabolism. A previous study suggested that the overexpression of FoxO1 in mouse livers contributes to the progression of hepatic steatosis through increased TG accumulation and decreased FA oxidation (14). Haeusler et al also demonstrated that hepatic FoxO1 ablation exacerbated lipid abnormalities during hyperglycemia (20). Furthermore, abnormal morphology, function and the biogenesis of mitochondria have been observed in the livers of insulin receptor substrate (IRS)-1/2 double-knockout mice (21), in association with the increased expression of FoxO1. In addition, the expression of mitochondrial genes was partially restored to normal levels upon the deletion of FoxO1 (21).

The endocannabinoid system, consisting of the cannabinoid receptor, endogenous cannabinoid ligands and their biosynthetic and degradative enzymes, has emerged as an ubiquitous system with key functions in various physiological settings. Cannabinoid receptor type 1 (CB1R) is widely distributed in the brain (22), and also exists peripherally, including in the liver tissue (23). The dysregulation of CB1R-mediated pathways is the major determinant in several key aspects of liver pathogenesis. Osei-Hyiaman et al reported that increases in hepatic CB1R density and basal rates of FA synthesis were observed in mice with DIO (23), which further contributes to liver steatosis, dyslipidemia, insulin resistance and leptin resistance (24), and is partially reversed by the antagonism of or a genetic deficiency of CB1R $(23,24)$. In this regard, the mechanisms of the endoplasmic reticulum (ER) stress-dependent increase in ceramide synthesis and cyclic AMP response element-binding protein $\mathrm{H}(\mathrm{CREBH})$-mediated Lipin 1 gene expression, were portrayed as playing a key role in diet-induced, CB1R-mediated hepatic insulin resistance in vivo $(25,26)$. Furthermore, a consumption of a high-fat diet (HFD) has been shown to induce hepatic insulin resistance in mice through the CB1Rmediated inhibition of insulin signaling and clearance (27). Despite concerns regarding the neuropsychiatric side-effects of brain-penetrant CB1R antagonists, the selective targeting of peripheral CB1Rs is of potential value to the management of obesity-related metabolic abnormalities without causing behavioral effects $(28,29)$. A previous study reported that CB1R stimulation decreased mitochondrial biogenesis in white adipocytes and impaired mitochondria in the metabolically-active tissue of dietary obese mice fed a HFD (30). Thus, the present study aimed to investigate whether FoxO1 plays a pivotal role in CB1R-mediated insulin resistance through the dysregulation of mitochondrial function in the livers of with DIO.

\section{Materials and methods}

Animals. A total of 50 male C57BL/6 mice (3-4 weeks old, weighing $15.2 \pm 3.7 \mathrm{gm}$ ) were purchased from the National Laboratory Animal Center (Taipei, Taiwan) and housed in a temperature-controlled environment $\left(20 \pm 2^{\circ} \mathrm{C}\right)$ under a $12-\mathrm{h}$ light/dark cycle. The mice were fed either a standard diet (STD; $13.5 \%$ calories from fat, LabDiet 5001; LabDiet, St. Louis, MO, USA) or a HFD (60\% calories from fat, TestDiet $58 \mathrm{G} 9$; TestDiet, St. Louis, MO, USA) ad libitum for 12 weeks. The HFD-fed mice were then randomly divided into 3 subgroups, to receive once daily intraperitoneal (i.p.) injections of the vehicle (7.7\% DMSO, 4.6\% Tween-80, $87.7 \%$ saline), or 1 or $5 \mathrm{mg} / \mathrm{kg}$ body weight of the CB1R inverse agonist, AM251, for 7 days. The mice were weighed in conscious state by using an electric balance at the start of the experiment, prior to the administration of AM251, and prior to sacrifice. At the end of the 13th week, the mice were fasted for $12 \mathrm{~h}$ and anesthetized by $\mathrm{CO}_{2}$ inhalation prior to decapitation. Blood samples were collected for determining the biochemical parameters, and liver tissues were exsanguinated and frozen immediately in liquid nitrogen and stored at $-80^{\circ} \mathrm{C}$ for further analysis. All animal experimental protocols were approved by the Institutional Animal Care and Use Committee of Taipei Veterans General Hospital (Taipei, Taiwan).

Cell culture and preparation of medium containing a high concentration of long-chain free fatty acids (HFFA). Mouse AML12 hepatocyte-derived cells were obtained from the Food Industry Research and Development Institute (Hsinchu, Taiwan). The AML12 cells were grown in a 1:1 mixture of Dulbecco's modified Eagle's medium (DMEM)/F12 medium (Gibco, Grand Island, NY, USA) containing 10\% fetal bovine serum (FBS), $5 \mu \mathrm{g} / \mathrm{ml}$ insulin, $5 \mu \mathrm{g} / \mathrm{ml}$ transferrin, $5 \mathrm{ng} / \mathrm{ml}$ selenium and $40 \mathrm{ng} / \mathrm{ml}$ dexamethasone, and maintained at $37^{\circ} \mathrm{C}$ in a humidified environment with $5 \% \mathrm{CO}_{2} / 95 \%$ air atmosphere. In addition, HFFA medium was prepared according to the method described in the study by Kohli et al (31) with slight modifications. Briefly, HFFA medium was prepared by the addition of $2: 1$ oleate/palmitate mixture to pre-warmed culture medium $\left(37^{\circ} \mathrm{C}\right)$, followed by the addition of fatty acidfree BSA (at 5:1 molar ratio) and then gently mixing for $8 \mathrm{~h}$ at room temperature. For the ACEA medium, 1.0 mM ACEA prepared in DMSO was serial diluted and added to the culture medium to the final concentrations at $1.0,0.1$ or $0.01 \mu \mathrm{M}$.

Histopathological analysis. For hematoxylin and eosin (H\&E) staining, liver tissue was fixed in $4 \%$ paraformaldehyde, embedded in paraffin, cut into 5- $\mu \mathrm{m}$-thick sections, and stained with $\mathrm{H} \& \mathrm{E}$, followed by microscopic examination. For CB1R immunohistochemistry (IHC), the slides were deparaffinized and hydrated with ethanol, then sequentially incubated in $0.3 \% \mathrm{H}_{2} \mathrm{O}_{2}$ to block endogenous peroxidase activity, a specific 
rabbit anti-human CB1R antibody (ALX-215-055; Enzo Life Sciences, Inc., Plymouth Meeting, PA, USA) for $2 \mathrm{~h}$ at room temperature, and a biotinylated secondary antibody (goat antirabbit, \#31460; Thermo Fisher Scientific, Rockford, IL, USA) and avidin-biotin complex (ABC) reagent (Zymed Laboratories, San Francisco, CA, USA). Finally, color development was induced by 3,3'-diaminobenzidine (DAB) for $15 \mathrm{~min}$ and visualized under a light microscope (XI71, Olympus, Tokyo, Japan).

Plasma biochemical parameters. The plasma glucose level was assayed using a glucose analyzer (YSI 2300 STAT Plus; YSI Life Sciences, Yellow Springs, OH, USA), and the plasma insulin level was measured using a commercial enzyme-linked immunosorbent assay (ELISA) kit (Millipore Corp., Billerica, MA, USA). The plasma levels of alanine transaminase (ALT), aspartate transaminase (AST), TG, free FAs and cholesterol were determined using colorimetric methods according to the manufacturer's instructions. The homeostatic model assessment of insulin resistance (HOMA-IR) index was calculated using the following formula: fasting insulin levels $(\mu \mathrm{U} / \mathrm{ml}) \times$ fasting glucose levels $(\mathrm{mmol} / \mathrm{l}) / 22.5$.

Reverse transcription-quantitative (real-time) polymerase chain reaction $(R T-q P C R)$. Total RNA was extracted from the liver tissues using the guanidinium-phenol-chloroform extraction method, and the concentration and integrity of the isolated RNA were determined at OD 260/280. Total RNA (5 $\mu \mathrm{g})$ was reverse-transcribed into cDNA using the RevertAid ${ }^{\mathrm{TM}}$ First Strand cDNA Synthesis kit (Thermo Fisher Scientific, Waltham, MA, USA), followed by conducting qPCR using the SYBR system on a LightCycler 1.5 apparatus (both from Roche Applied Science, Mannheim, Germany). The PCR reaction was performed under the following conditions: $95^{\circ} \mathrm{C}$ for $10 \mathrm{~min}$ and then 45 cycles of $95^{\circ} \mathrm{C}$ for $15 \mathrm{sec}, 57^{\circ} \mathrm{C}$ for $30 \mathrm{sec}$ and $72^{\circ} \mathrm{C}$ for $30 \mathrm{sec}$. The PCR data were normalized to GAPDH expression as an internal control. The sequences of primers used for RT-qPCR are listed in Table I.

Immunoprecipitation and western blot analysis. The liver tissues were homogenized in ice-cold lysis buffer [50 mM Tris-HCl (pH 7.4), $100 \mu \mathrm{M}$ EDTA, $100 \mu \mathrm{M}$ EGTA, $12 \mathrm{mM}$ 2-mercaptoethanol, 1\% phosphatase inhibitor cocktail 2, and protease inhibitor cocktail], followed by centrifugation at $13,000 \mathrm{x} \mathrm{g}$ for $30 \mathrm{~min}$ at $4^{\circ} \mathrm{C}$ to harvest the protein lysates. For immunoprecipitation, an equal concentration of protein lysate was conjugated with anti-IRS-2 antibody at $4^{\circ} \mathrm{C}$ for $1 \mathrm{~h}$ and immunoprecipitated using Protein G PLUS-Agarose (both from Santa Cruz Biotechnology, Inc., Santa Cruz, CA, USA) and gently shaken for $12 \mathrm{~h}$ at $4^{\circ} \mathrm{C}$. The protein lysates were separated using SDS-PAGE and transferred onto PVDF membranes. The membranes were blocked with 5\% non-fat milk in TBS-T buffer for $1 \mathrm{~h}$ at room temperature, and incubated overnight at $4^{\circ} \mathrm{C}$ with various primary antibodies including CB1R (Enzo Life Sciences, Inc.), phosphorylated (p)-FoxO1 (\#9461), FoxO1 (\#2880), glutathione S-transferase (GST; \#2624) (all from Cell Signaling Technology, Inc., Beverly, MA, USA) and IRS-2 (\#8299), p-Tyr (\#7020), AKT (\#8312), p-AKT (\#7985-R), PI3K (\#71891), p-PI3K (\#293115), PEPCK (\#166778), G6Pase- $\alpha$ (\#25840, all from Santa Cruz Biotechnology, Inc.). The membranes were subsequently incubated with secondary
Table I. Sequences of primers used for RT-qPCR.

Gene Primer sequences

CB1R F: 5'-CTACTGGTGCTGTGTGTCATC-3'

R: 5'-GCTGTCTTTACGGTGGAATAC-3'

FoxO1 F: 5'-AGATGAGTGCCCTGGGCAGC-3' R: 5'-GATGGACTCCATGTCACAGT-3'

CPT-1 F: 5'-TGAGTGGCGTCCTCTTTGG-3' R: 5'-CAGCGAGTAGCGCATAGTCA-3'

PGC-1 $\alpha$ F: 5'-GACTCAGTGTCACCACCGAAA-3' R: 5'-TGAACGAGCGCATCCTT-3'

TFAM F: 5'-GGAATGTGGAGCGTGCTAAA-3' R: 5'-TGCTGGAAAAACACTTCGGAATA-3'

NRF-1 F: 5'-CGCAGCACCTTTGGAGAA-3' R: 5'-CCCGACCTGTGGAATACTTG-3'

NRF-2 F: 5'-ATGGATTTGATTGACATCCTT-3' R: 5'-CATGTTTTTCTTTGTATCTGG-3'

Citrate F: 5'-GCCATCACAGCCCTCAAC-3' synthase R: 5'-GCAATCAGGTCCATACAGTCTTC-3'

PEPCK F: 5'-AGCCTGCTCCAGCTTTGA-3' R: 5'-CCCTAGCCTGTTCTCTGTGC-3'

G6Pase F: 5'-TGCTGTGTCTGGTAGGCAAC-3' R: 5'-AGAATCCTGGGTCTCCTTGC-3'

GAPDH F: 5'-TCACCACCATGGAGAAGGC-3' R: 5'-GCTAAGCAGTTGGTGGTGCA-3'

mtDNA F: 5'-AACTCAAAGGACTTGGCGGTACTTTATATC-3' R: 5'-GATGGCGGTATATAGGCTGAATTAGCAAGAG-3'

28S F: 5'-GGCGGCCAAGCGTTCATAC-3' R: 5'-AGGCGTTCAGTCATAATCCCACAG-3'

F, forward; R, reverse; CB1R, cannabinoid receptor type 1; FoxO1, forkhead box O1; CPT-1, carnitine palmitoyltransferase-1; PGC-1 $\alpha$, peroxisome proliferator-activated receptor $\gamma$ co-activator-1 $\alpha$; TFAM, mitochondrial transcription factor A; NRF-1, nuclear respiratory factor-1; PEPCK, phosphoenolpyruvate carboxykinase; G6Pase, glucose 6-phosphatase; mtDNA, mitochondrial DNA.

antibodies (\#31430 or \#31460; Thermo Fisher Scientific, Rockford, IL, USA) for $1 \mathrm{~h}$ at room temperature. The signals were detected using an enhanced chemiluminescence kit (Millipore Corp.), and quantified using ImageQuant 5.2 software, and calibrated using $\beta$-actin as an internal control.

Mitochondrial DNA and ATP assay. The mtDNA copy number was determined by qPCR, as previously described by Tedesco et al (32). Briefly, genomic DNA was isolated from the liver tissue using the DNA extraction kit (Promega Corp., Madison, WI, USA). qPCR was conducted using the SYBR system on a LightCycler 1.5 apparatus. The ratio of mtDNA to nuclear DNA and mtDNA was reflected in the mitochondria concentration. The primer sequences of mtDNA and nuclear DNA are listed in Table I. For the ATP assay, the ATP content of the liver tissues was measured using the ATP Bioluminescence Assay kit HS II (Roche Applied Science) according to the manufacturer's instructions. The luminescence value was normalized 
Table II. Effects of AM251 on physical parameters in HFD-fed mice.

\begin{tabular}{|c|c|c|c|c|}
\hline & STD & HFD & $\mathrm{HFD}+\mathrm{AM} 2511 \mathrm{mg} / \mathrm{kg}$ & $\mathrm{HFD}+\mathrm{AM} 2515 \mathrm{mg} / \mathrm{kg}$ \\
\hline Body weight (g) & $25.87 \pm 4.39^{\mathrm{a}}$ & $43.13 \pm 5.54^{\mathrm{b}}$ & $37.53 \pm 8.54^{\mathrm{b}}$ & $31.88 \pm 7.84^{\mathrm{a}}$ \\
\hline Liver weight (g) & $1.38 \pm 0.32^{\mathrm{a}}$ & $2.08 \pm 0.23^{\mathrm{a}}$ & $1.99 \pm 0.85^{\mathrm{a}}$ & $1.66 \pm 0.49^{\mathrm{a}}$ \\
\hline Plasma TG (mg/dl) & $81.73 \pm 5.64^{\mathrm{a}}$ & $129.35 \pm 12.36^{\mathrm{b}}$ & $127.37 \pm 16.35^{\mathrm{b}}$ & $102.46 \pm 9.87^{c}$ \\
\hline Plasma FFAs (mmol/l) & $0.34 \pm 0.08^{\mathrm{a}}$ & $0.49 \pm 0.12^{\mathrm{b}}$ & $0.45 \pm 0.17^{\mathrm{b}}$ & $0.42 \pm 0.18^{\mathrm{b}}$ \\
\hline Plasma cholesterol (mg/dl) & $73.38 \pm 10.64^{\mathrm{a}}$ & $90.35 \pm 19.03^{\mathrm{a}}$ & $93.86 \pm 20.14^{\mathrm{a}}$ & $87.63 \pm 16.73^{\mathrm{a}}$ \\
\hline Plasma glucose (mmol/l) & $2.13 \pm 0.19^{\mathrm{a}}$ & $4.42 \pm 0.33^{\mathrm{b}}$ & $3.92 \pm 0.22^{\mathrm{b}}$ & $2.88 \pm 0.27^{\mathrm{c}}$ \\
\hline Plasma insulin $(\mu \mathrm{U} / \mathrm{ml})$ & $12.63 \pm 1.27^{\mathrm{a}}$ & $25.36 \pm 4.23^{\mathrm{b}}$ & $22.48 \pm 5.34^{\mathrm{b}}$ & $18.83 \pm 3.87^{\mathrm{b}}$ \\
\hline HOMA-IR index & $1.20 \pm 0.01^{\mathrm{a}}$ & $4.98 \pm 0.06^{\mathrm{b}}$ & $3.91 \pm 0.05^{\mathrm{b}}$ & $2.41 \pm 0.05^{\mathrm{c}}$ \\
\hline ALT (U/l) & $57.16 \pm 8.09^{\mathrm{a}}$ & $65.27 \pm 9.34^{\mathrm{a}}$ & $68.13 \pm 8.15^{\mathrm{a}}$ & $58.36 \pm 8.37^{\mathrm{a}}$ \\
\hline AST (U/l) & $81.16 \pm 5.19^{a}$ & $95.27 \pm 15.82^{\mathrm{a}}$ & $97.96 \pm 12.42^{\mathrm{a}}$ & $98.36 \pm 9.73^{\mathrm{a}}$ \\
\hline
\end{tabular}

Data are expressed as the means \pm SEM and each group consisted of 4-5 mice. Values marked by different superscript letters denote statistically significant differences $(\mathrm{P}<0.05)$ between groups, according to Tukey's post hoc tests. STD, standard diet; HFD, high-fat diet; HOMA-IR, homeostatic model assessment for insulin resistance; ALT, alanine transaminase; AST, aspartate transaminase.

by the protein concentration and the differences among groups were compared.

Liver lipid peroxidation, superoxide dismutase (SOD) and GSH assays. A lipid peroxidation assay was performed by measuring the production rate of thiobarbituric acid-reactive substances (TBARS) and expressed as malondialdehyde (MDA) equivalents. The amount of MDA was assessed by measuring the OD535 $\mathrm{nm}$ at $37^{\circ} \mathrm{C}$ and the results were expressed as $\mathrm{nmol} / \mathrm{mg}$ protein. The SOD and GSH levels in the liver samples were measured using the Superoxide Dismutase Assay kit and the Glutathione Assay kit (Cayman Chemical Co., Ann Arbor, MI, USA), respectively, according to the manufacturer's instructions.

Gene silencing with small interfering RNA (siRNA) against FoxO1. The FoxO1 gene was silenced using Dharmacon ${ }^{\mathrm{TM}}$ siRNA (GE Dharmacon, Lafayette, CO, USA) according to the manufacturer's instructions. The siRNA duplex nucleotides were designed for the specific silencing of FoxO1 (5'-GGUGU CAGGCUAAGAGUUA-3') or scrambled control (5'-GGUGU CGGACUAAGAGUUA-3'). The cells were transfected using DharmaFECT 1 transfection reagent combined with either $100 \mathrm{nM}$ FoxO1 or scrambled control siRNA duplex in DMEM/ F12 culture medium without antibiotics. After $72 \mathrm{~h}$, the cells were treated with medium containing HFFA or arachidonyl-2'chloroethylamide (ACEA; a selective CB1R agonist) and harvested for gene expression analysis. For other experimental conditions, $100 \mu \mathrm{M}$ c-AMP/500 nM dexamethasone (c-AMP/ Dex) and $10^{-7} \mathrm{M}$ insulin were applied to evaluate the typical physiological response of the cells and the effects on PEPCK and G6Pase as reported previously (33).

Statistical analysis. Data are expressed as the means \pm SEM of at least 3 independent measurements and compared using the Student's t-test. A value of $\mathrm{P}<0.05$ was considered to indicate a statistically significant difference. Comparisons among groups were performed using one-way analysis of variance (ANOVA), followed by multiple comparison procedures used to identify significant differences among groups. The physical parameters were analyzed using one-way ANOVA, and subsequent Tukey's post hoc tests for multiple comparisons were conducted.

\section{Results}

Effects of AM251 on body weight, liver weight and plasma biochemical parameters. The HFD-fed mice exhibited a significant increase in body weight and in the plasma levels of TG, FFAs, glucose and insulin, which resulted in a higher HOMA-IR index value compared with that of the STD-fed (control) mice (Table II). However, an increasing trend in plasma cholesterol, ALT and AST levels, as well as liver weight was observed in the HFD-fed mice. The blockade of the cannabinoid receptor by treatment with $5 \mathrm{mg} / \mathrm{kg}$ AM251, but not $1 \mathrm{mg} / \mathrm{kg}$, significantly reduced body weight and suppressed the elevated levels of TG, glucose and the HOMA-IR index in HFD-fed mice; however, the magnitude of suppression did not reach the levels observed in the STD-fed mice.

Effects of AM251 on histopathological changes and CB1R levels in liver tissue. The results of $\mathrm{H} \& \mathrm{E}$ staining of the liver tissue samples indicated that fatty degeneration and piecemeal necrosis of hepatocytes were more obvious in the HFD-fed mice than in the STD-fed mice, and these phenomena were reversed by treatment with $5 \mathrm{mg} / \mathrm{kg}$ AM251 (Fig. 1A, upper panels). IHC staining revealed that the administration of $5 \mathrm{mg} / \mathrm{kg}$ AM251 also decreased the hepatic CB1R content in the HFD-fed mice (Fig. 1A, lower panels; arrows depict the sites of CB1R expression). In addition, the mRNA and protein expression levels of CB1R were significantly increased in the liver tissues isolated from the HFD-fed mice; however, only the protein levels were significantly decreased by treatment with AM251 at a dose of $5 \mathrm{mg} / \mathrm{kg}$ (Fig. $1 \mathrm{~B}$ and C).

Effect of AM251 on insulin signaling and FoxOl activity in liver tissue. A previous study indicated that reducing FoxO1 

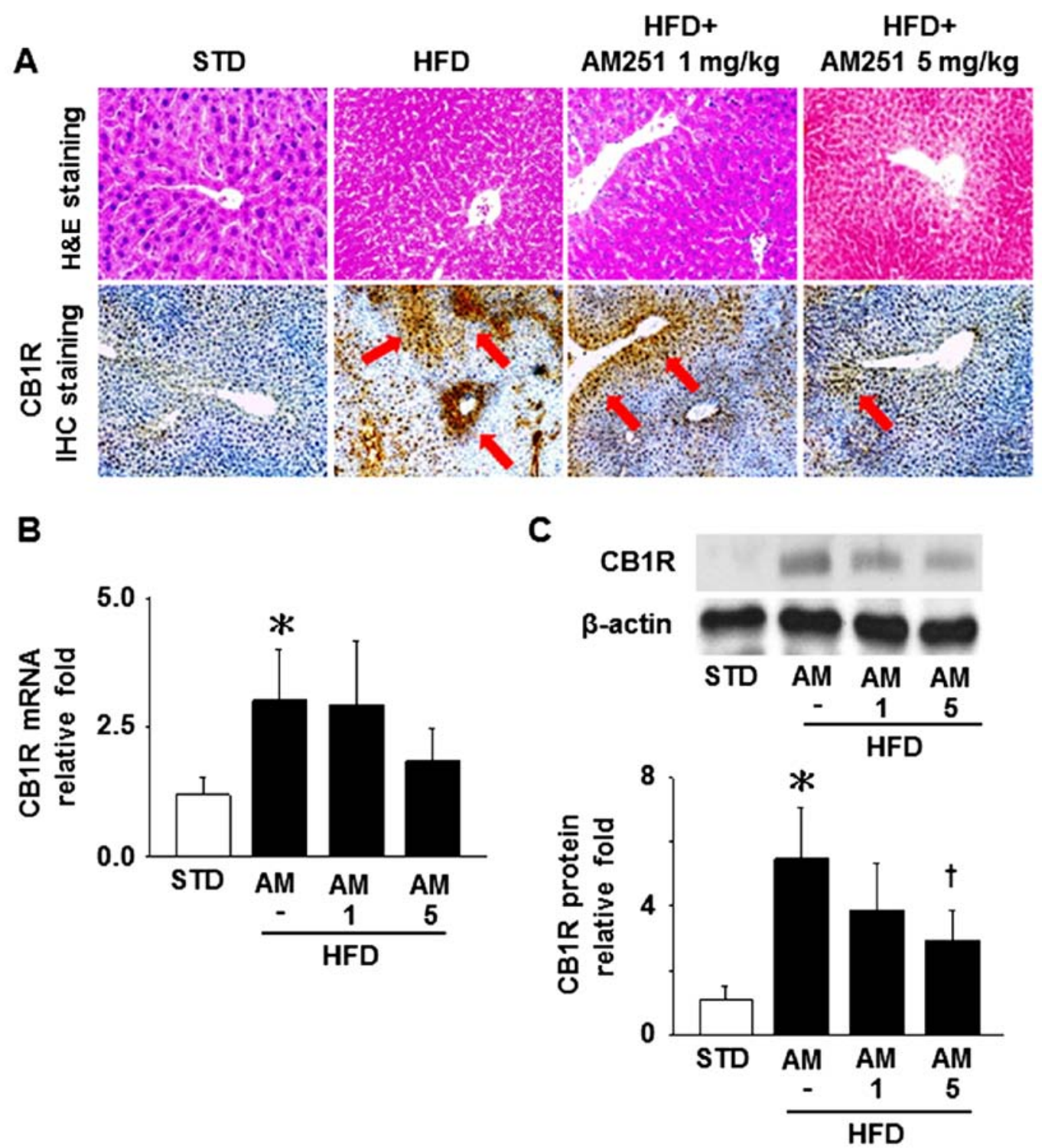

Figure 1. Effects of AM251 on histopathological changes and cannabinoid receptor type 1 (CB1R) expression in the liver tissue isolated from high-fat diet (HFD)-fed mice. (A) Liver tissues from standard diet (STD)- and HFD-fed mice treated with 1 and $5 \mathrm{mg} / \mathrm{kg}$ AM251 were obtained and fixed in 4\% paraformaldehyde for H\&E staining and CB1R IHC staining. IHC staining for CB1R is indicated by a dark-brown color (shown by red arrows). The results are shown at 200 magnification. (B) The mRNA and (C) protein levels of CB1R in liver tissues from STD- and HFD-fed mice treated with or without AM251 were detected by RT-qPCR and western blot anlaysis, respectively. The data are presented as the means \pm SEM from 3 independent measurements. ${ }^{*} \mathrm{P}<0.05$ vs. STD-fed mice; ${ }^{\dagger} \mathrm{P}<0.05$ vs. HFD-fed mice.

expression in the liver using an antisense oligonucleotidemediated approach improved glucose tolerance and insulin resistance in obese mice (13). Thus, in this study, we wished to examine whether a possible association exists between hepatic CB1R expression and FoxO1 activity in HFD-fed mice. As shown in Fig. 2A, treatment with $5 \mathrm{mg} / \mathrm{kg}$ AM 251 significantly upregulated the levels of hepatic IRS-2, PI3K and AKT phosphorylation in the mice which had been reduced due to a HFD. In parallel, the FoxO1 phosphorylation levels decreased and increased in the livers of the HFD-fed mice in the presence and absence of AM251, respectively (Fig. 2C), although the FoxO1 mRNA level did not differ significantly among these 4 groups (STD, HFD, HFD plus $1 \mathrm{mg} / \mathrm{kg}$ AM251 and HFD plus $5 \mathrm{mg} / \mathrm{kg}$ AM251; Fig. 2B). These results suggest that CB1R partially influences FoxO1 activity by suppressing the insulin signaling pathway in mice fed a HFD.
Effects of AM251 on mitochondrial dysfunction and oxidative stress in liver tissue. Our results indicated that the mRNA levels of carnitine palmitoyltransferase-1 (CPT-1, a mitochondrial enzyme responsible for FA $\beta$-oxidation), mitochondrial biogenesis-related factors, such as mitochondrial transcription factor A (TFAM) and nuclear respiratory factor-1 (NRF-1), as well as citrate synthase (a pace-making enzyme of the Krebs cycle) in the liver tissue were markedly decreased in the mice fed a HFD compared to the mice fed a STD (control); however, this effect was attenuated by treatment with $5 \mathrm{mg} / \mathrm{kg}$ AM251 (Fig. 3A, B and D). However, no statistically significant difference was observed in the levels of peroxisome proliferatoractivated receptor $\gamma$ co-activator-1 $\alpha$ (PGC-1 $\alpha$ ) and NRF-2, two other factors controlling mitochondrial biogenesis, as well as in the mtDNA copy number, among these 4 groups (STD, HFD, HFD plus $1 \mathrm{mg} / \mathrm{kg} \mathrm{AM} 251$ and HFD plus $5 \mathrm{mg} / \mathrm{kg}$ AM251; 
A

$A_{\text {p-Tyr (IB) }}$

IRS-2 (IP)

p-PI3K

PI3K

P-AKT

AKT

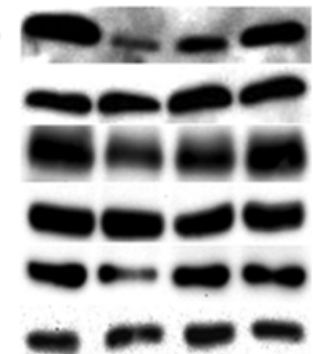

STD

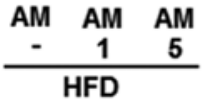

$\square \mathrm{STD} \square \mathrm{HFD}+\mathrm{AM} 1 \mathrm{mg} / \mathrm{kg}$

- $\mathrm{HFD} \quad \mathrm{HFD}+\mathrm{AM} 5 \mathrm{mg} / \mathrm{kg}$

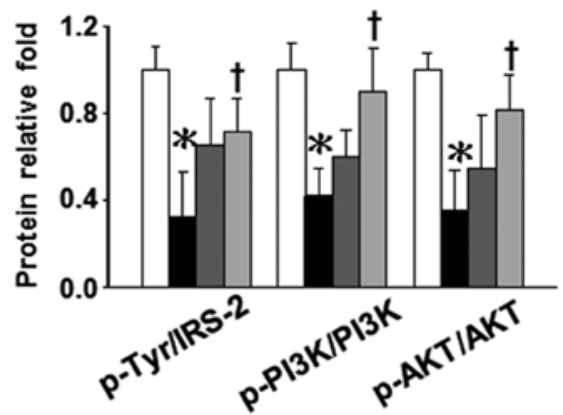

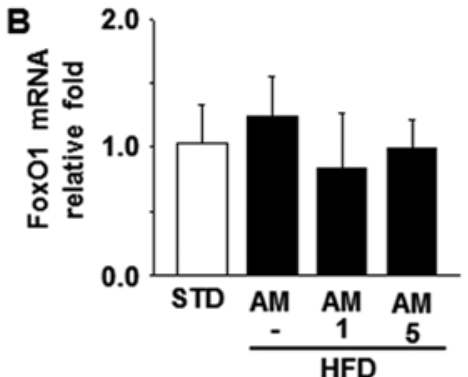

$C_{\text {p-FoxO1 }}$

Fox01
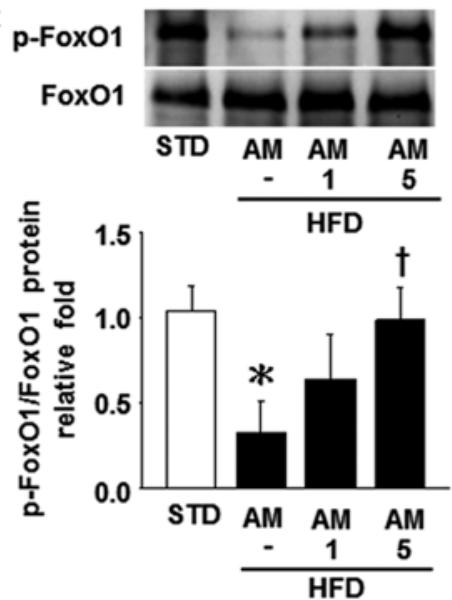

Figure 2. Effects of AM251 on insulin signaling and forkhead box O1 (FoxO1) expression in liver tissue isolated from high-fat diet (HFD)-fed mice. (A) Total and phosphorylated (p-) forms of PI3K and AKT were detected by western blot analysis. Liver protein lysates were conjugated with the anti-IRS-2 antibody for immunoprecipitation, and subsequently probed using the anti-p-tyrosine kinase antibody. (B and C) Hepatic FoxO1 mRNA and protein phosphorylation levels were detected by RT-qPCR and western blot analysis, respectively. Data are shown as the means \pm SEM from 3 independent measurements. "P $<0.05$ vs. standard diet (STD)-fed mice; ${ }^{\dagger} \mathrm{P}<0.05$ vs. HFD-fed mice.

\section{A}

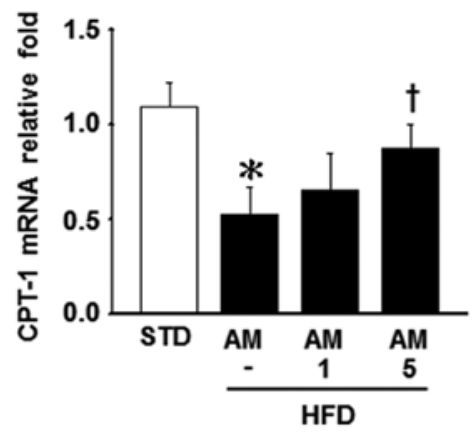

B

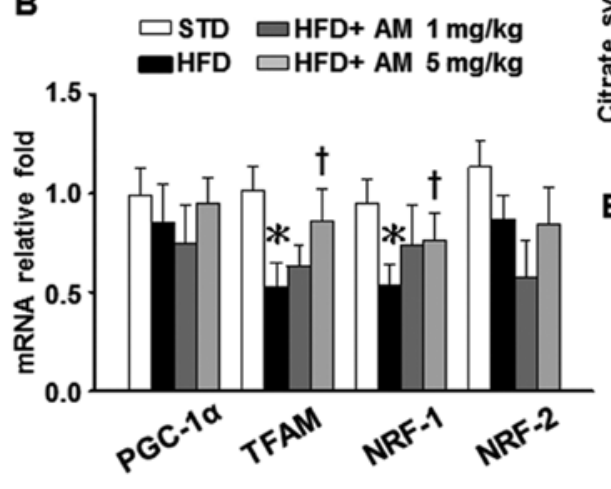

C

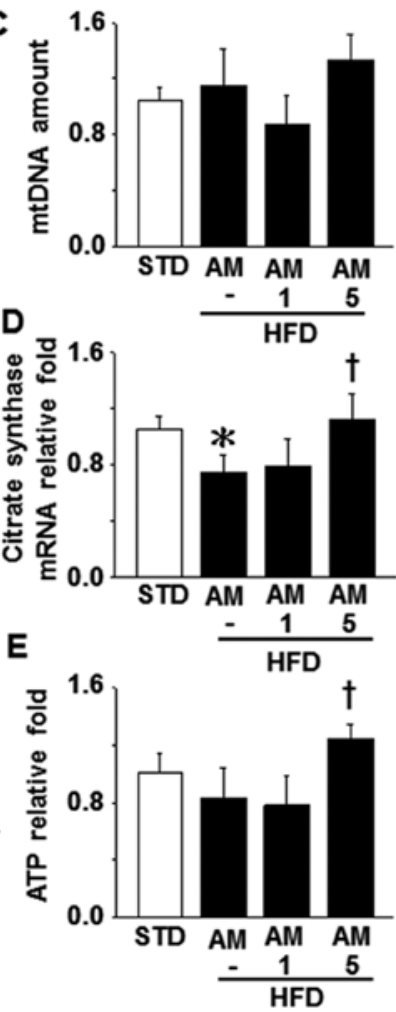

Figure 3. Effects of AM251 on mitochondrial dysfunction in the livers of high-fat diet (HFD)-fed mice. RT-qPCR results showing the mRNA levels of (A) CPT-1, (B) peroxisome proliferator-activated receptor $\gamma$ coactivator-1 $\alpha$ (PGC-1 $\alpha$ ), mitochondrial transcription factor A (TFAM), nuclear respiratory factor-1 (NRF-1), NRF-2, and (D) citrate synthase. (C) The hepatic mtDNA amount was measured by qPCR and is presented as the mtDNA copy number per nuclear DNA copy number. (E) The relative liver ATP levels were analyzed using the ATP Bioluminescence Assay kit, and the differences among groups were compared. Values are expressed as the means \pm SEM from 3 independent measurements. ${ }^{*} \mathrm{P}<0.05$ vs. standard diet (STD)-fed mice; ${ }^{\dagger} \mathrm{P}<0.05$ vs. HFD-fed mice. 

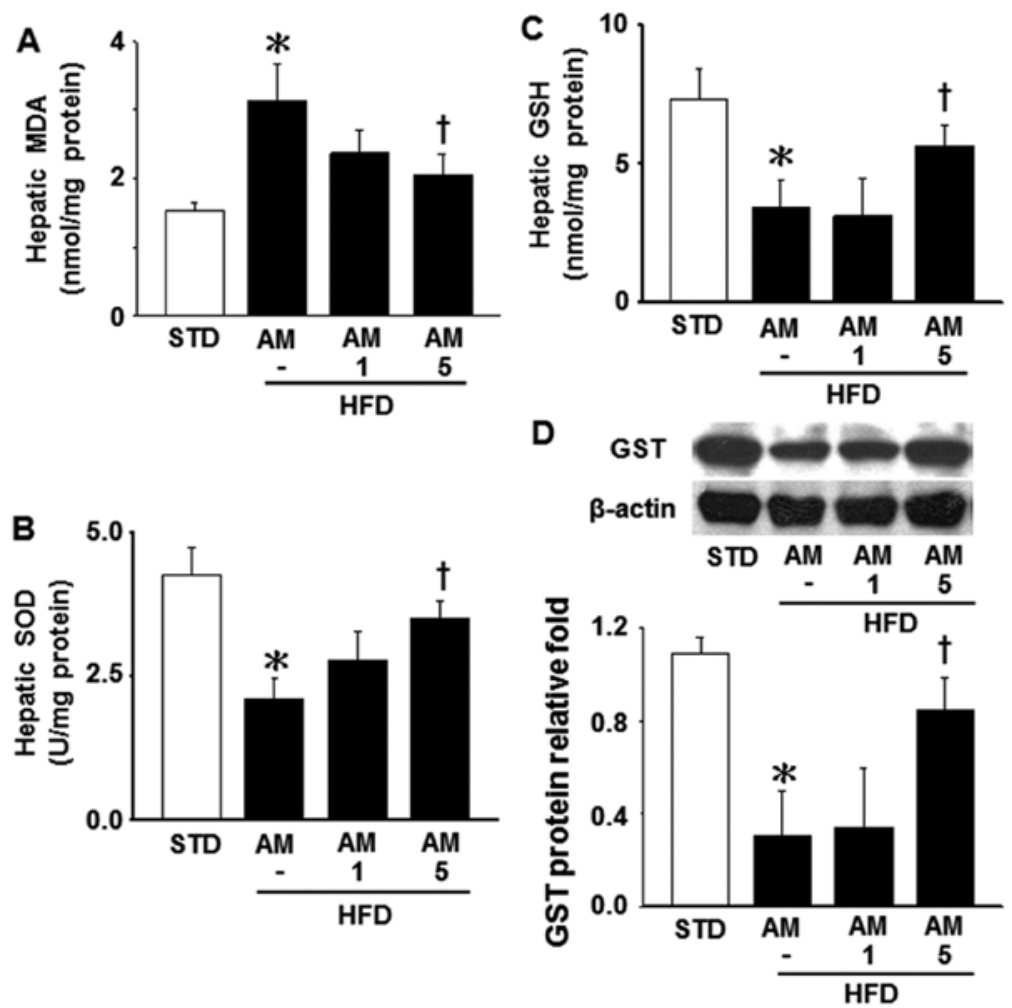

Figure 4. Effects of AM251 on hepatic oxidative stress in high-fat diet (HFD)-fed mice. (A) Hepatic lipid peroxidation level is represented as thiobarbituric acid reactive substances (TBARS). Hepatic (B) superoxide dismutase (SOD) and (C) glutathione (GSH) assays were performed as described in the Materials and methods. (D) Liver protein lysates were analyzed by western blot anlaysis with antibody against glutathione S-transferase (GST). Data are shown as the means \pm SEM from 3 independent measurements. ${ }^{*} \mathrm{P}<0.05$ vs. standard diet (STD)-fed mice; ${ }^{\dagger} \mathrm{P}<0.05$ vs. HFD-fed mice.

Fig. 3B and C). The hepatic ATP level in the HFD-fed mice that were administered $5 \mathrm{mg} / \mathrm{kg}$ AM251 was higher than that in the HFD-fed mice not administered AM251; however, the ATP level did not decrease significantly in the untreated HFD-fed mice compared with the STD-fed mice (Fig. 3E). In addition, the MDA level, which was measured to evaluate the production of lipid peroxide, was significantly increased in the HFD-fed mice compared with the STD-fed mice (Fig. 4A). The administration of AM 251 at the dose of $5 \mathrm{mg} / \mathrm{kg}$ significantly attenuated the increase in the MDA level in the HFD-fed mice (Fig. 4A). Conversely, a HFD led to a significant decrease in hepatic SOD and GSH activity, as well as the GST level; these effects were attenuated by treatment with $5 \mathrm{mg} / \mathrm{kg}$ AM251 (Fig. 4B-D). These observations indicate that AM251 attenuates obesityinduced mitochondrial dysfunction, the decrease in SOD and GSH levels, and lipid peroxidation.

Effects of AM251 on the levels of PEPCK and G6Pase in liver tissue. PEPCK and G6Pase are critically involved in gluconeogenesis and they have been identified as indicators of hepatic insulin resistance (34). Hence, in this study, we aimed to determine whether the expression of hepatic PEPCK and G6Pase is affected a HFD. A HFD resulted in a marked increased in the mRNA and protein levels of PEPCK and G6Pase compared with the STD (control mice). By contrast, the increase in the levels of PEPCK and G6Pase was significantly abolished by treatment with $5 \mathrm{mg} / \mathrm{kg}$ AM251 in the HFD-fed mice; however, the G6Pase mRNA level was not significanly affected by treatment with AM251 (Fig. 5).
Effects of FoxOl on mitochondrial function, and the levels of PEPCK and G6Pase in AML12 hepatocytes. In order to mimic the elevated levels of plasma FFAs and hepatic FoxO1 activity as observed in our HFD-fed mice, AML12 hepatocytes were cultured in HFFA-containing medium. In this way, we aimed to further explore a series of mechanisms between CB1R and FoxO1. The phosphorylation levels of FoxO1 and AKT were markedly decreased in the cells cultured in $1 \mathrm{mM}$ HFFA compared to the cells cultured without HFFA (Fig. 6A). Subsequently, we transfected the cells with siRNA against FoxO1 in order to further verify the direct correlation between CB1R and FoxO1 activity, which may cause mitochondrial dysfunction and alterations in the levels of PEPCK and G6Pase due to the stimulation of FAs. Compared to the untreated cells or the scrambled controls, quantitative analysis of FoxO1 protein expression revealed an approximate $70 \%$ decrease in expression in the AML12 cells treated with $100 \mathrm{nM}$ siRNA against FoxO1 $(1.00 \pm 0.05,1.05 \pm 0.07$ and $0.31 \pm 0.10$, respectively; Fig. 6B). Furthermore, the mRNA levels of PGC-1 $\alpha$, TFAM, NRF-1 and NRF-2 were significantly decreased following the challenge with $1 \mathrm{mM}$ HFFA; however, transfection with siRNA against FoxO1 reversed the HFFA-induced decrease in the gene expression of the aforementioned regulators (Fig. 6C). The expression of PEPCK and G6Pase was increased in response to cAMP/Dex, but was reduced in response to insulin. Our results demonstrated that treatment with $1 \mathrm{mM}$ HFFA abolished the insulin-induced suppression of cAMP/Dex-mediated PEPCK and G6Pase levels. However, the silencing of FoxO1 markedly suppressed the expression of 

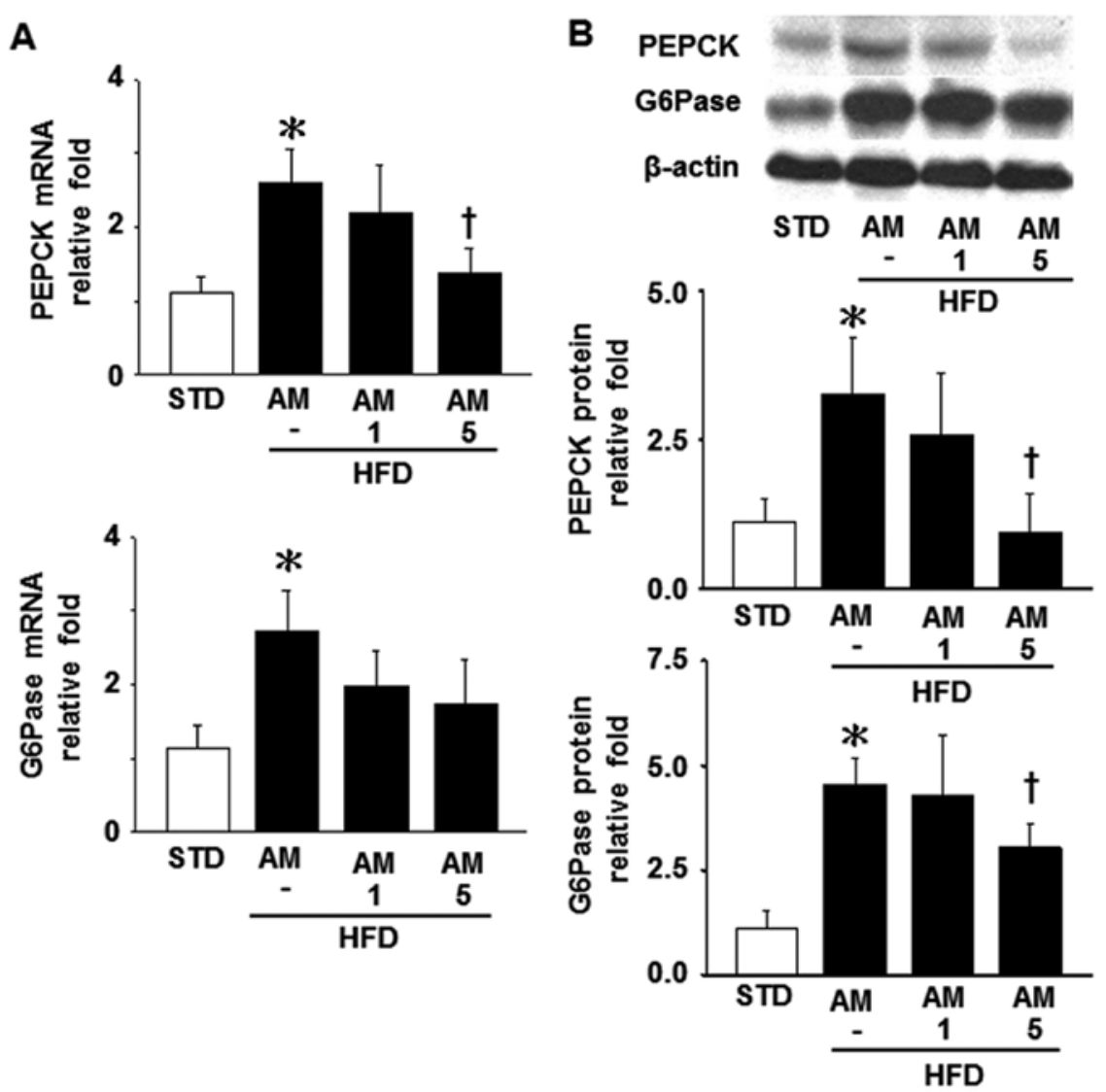

Figure 5. Effects of AM251 on hepatic phosphoenolpyruvate carboxykinase (PEPCK) and G6Pase levels in high-fat diet (HFD)-fed mice. (A) The mRNA and (B) protein levels of PEPCK and G6Pase of liver tissue from standard diet (STD)-fed mice and HFD-fed mice with or without AM251 treatment were detected by RT-qPCR and western blot analysis, respectively. Data are presented as the means \pm SEM from 3 independent measurements. ${ }^{*} \mathrm{P}<0.05$ vs. STD-fed mice; ${ }^{\dagger} \mathrm{P}<0.05$ vs. HFD-fed mice.

PEPCK and G6Pase as regards the aspects of gluconeogenesis associated with HFFA (Fig. 6D).

In line with the effects of HFFA on the expression of FoxO1 and AKT, the phosphorylation levels of FoxO1 and AKT were also markedly inhibited by treatment with $1 \mu \mathrm{M}$ ACEA (Fig. 7A). Furthermore, the silencing of the FoxO1 gene significantly attenuated the ACEA-induced decrease in the mRNA levels of PGC-1 $\alpha$, TFAM, NRF-1 and NRF-2, as well as the ACEA-induced increase in PEPCK and G6Pase levels which had been suppressed by insulin (Fig. 7B and C). Taken together, these results demonstrate that a direct association exists between $\mathrm{CB} 1 \mathrm{R}$ and FoxO1 in FA-induced mitochondrial dysfunction and insulin resistance in hepatocytes.

\section{Discussion}

Any impairment in hepatic insulin sensitivity is rapidly reflected in glucose homeostasis and triglyceride levels. Thus, fatty liver is considered the hepatic expression of metabolic syndrome (35). The present study demonstrated that the pharmacological blockade of CB1R improved hyperglycemia in mice, which was caused by a HFD, and partially decreased FoxO1-mediated insulin resistance by increasing the phosphorylation of insulin signaling cascades and ameliorating mitochondrial dysfunction in liver, indicating a high correlation between CB1R and FoxO1 activity in NAFLD and metabolic disorders. A HFD resulted in the upregulation of CB1R expression in the liver, but reduced the levels of mitochondrial enzymes (CPT-1 and citrate synthase), as well as those of mitochondrial biogenic factors (TFAM and NRF-1), which precede NAFLD development and insulin resistance. These changes occurred in conjunction with a decrease in glycemic control, the loss of hepatic antioxidant capacity, increased hepatic oxidative stress, and reduced hepatic mitochondrial function. The results were similar to those of the studies by Rector et al (8) and Osei-Hyiaman et al (23). On the other hand, a HFD led to significantly higher plasma levels of lipids (TG and FFAs), glucose and insulin compared with a STD (control mice), whereas elevated serum ALT and AST levels were not clearly observed in the HFD-fed mice. This indicated that the mouse model of DIO included only simple hepatosteatosis, and did not exhibit further transfer to NASH, although hepatic oxidative stress and lipid peroxidation significantly increased in the HFD-fed mice.

High carbohydrate diets, or excessive dietary fat leading to exaggerated FFA delivery has been shown to result in hepatic insulin resistance (36), diminished FA oxidation and increased DNL with TG accumulation in hepatocytes (37). In addition, high glucose and high FFA levels have been shown to induce marked insulin resistance and mitochondrial dysfunction in differentiated 3T3-L1 adipocytes, which results from increased levels of intracellular ROS and the loss of mitochondrial membrane potential (38). Moreover, recent studies have demonstrated that the administration of AM251 is a promising therapeutic strategy for the treatment of NAFLD or metabolic 
A

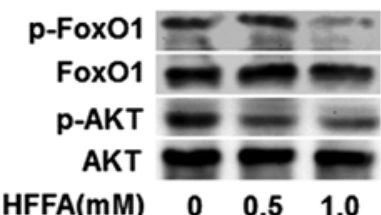

$\square$ HFFA $0 \mathrm{mM} \square$ HFFA $0.5 \mathrm{mM}$

HFFA $1.0 \mathrm{mM}$

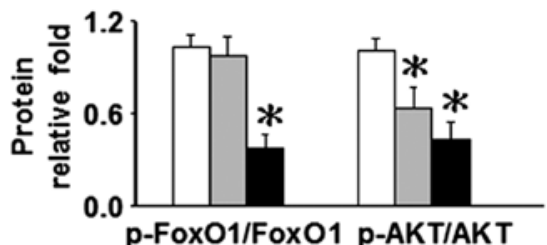

B
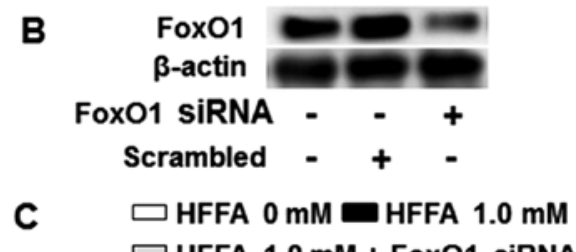
$\square$ HFFA $1.0 \mathrm{mM}+$ FoxO1 siRNA

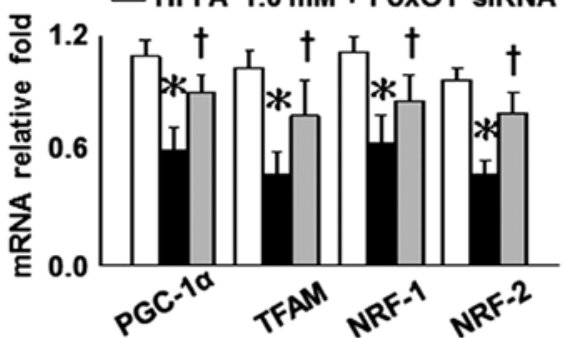

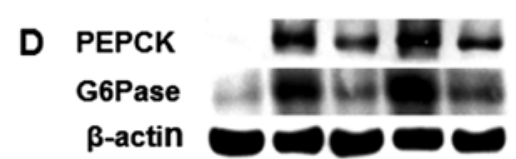
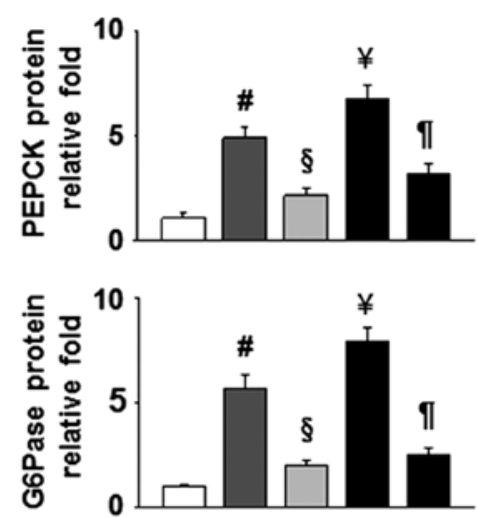

Fox01

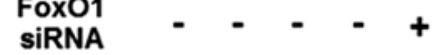

HFFA

(1.0 mM)

CAMPIDex - + + + +

Insulin $\left(10^{-7} \mathrm{M}\right)--+++$

Figure 6. Genetic ablation of forkhead box O1 (FoxO1) attenuates the HFFA-induced suppression of mitochondrial biogenesis and the inhibitory efects of HFFA on the insulin-induced suppression of phosphoenolpyruvate carboxykinase (PEPCK) and G6Pase levels in AML12 cells. (A) Total and phosphorylated (p-) protein levels of FoxO1 and AKT in AML12 cells challenged with 0.5 and $1.0 \mathrm{mM}$ of HFFA for $12 \mathrm{~h}$ detected by western blot analysis. (B) Altered expression of FoxO1 protein after the FoxO1 siRNA was introduced into AML12 cells via transient transfection. (C) The mRNA levels of peroxisome proliferator-activated receptor $\gamma$ coactivator-1 $\alpha$ (PGC-1 $\alpha$ ), mitochondrial transcription factor A (TFAM), nuclear respiratory factor-1 (NRF-1) and NRF-2 analyzed by RT-qPCR after FoxO1 gene ablation followed by exposure to $1.0 \mathrm{mM}$ HFFA for $12 \mathrm{~h}$. (D) Protein levels of PEPCK and G6Pase in AML12 cells after sequential treatments with FoxO1 siRNA, $1.0 \mathrm{mM}$ HFFA for $24 \mathrm{~h}, 10^{-7} \mathrm{M}$ insulin for $30 \mathrm{~min}$, and c-AMP $(100 \mu \mathrm{M}) /$ dexamethasone $(500 \mathrm{nM})$ (c-AMP/Dex) for $2 \mathrm{~h}$. Results are expressed as the means \pm SEM from 3 independent experiments. ${ }^{*} \mathrm{P}<0.05$ vs. 0 mM HFFA; ${ }^{\dagger} \mathrm{P}<0.05$ vs. 1 mM HFFA; ${ }^{\prime} \mathrm{P}<0.05$ vs. white bar (no treatment); ${ }^{\S} \mathrm{P}<0.05$ vs. dark gray bar; ${ }^{\sharp} \mathrm{P}<0.05$ vs. HFFA(-) + insulin + cAMP/Dex; ${ }^{9} \mathrm{P}<0.05$ vs. HFFA + insulin + cAMP/Dex.

syndrome (39-41). Our results indicated that a decrease in plasma TG and glucose levels, as well as in the HOMA-IR index value occurred in HFD-fed mice following the administration of $5 \mathrm{mg} / \mathrm{kg}$ AM251 was, but this did not significantly alter the plasma insulin levels in these groups. Thus, we speculated that although treatment with AM251 led to a lower plasma level of TG and glucose, it was insufficient to restrain insulin secretion or to enhance hepatic insulin clearance, as the plasma TG and glucose levels in the HFD-fed mice that received AM251 remained higher than those in the STD-control mice.

It has also been previously indicated that the blockade of CB1R suppresses the CB1R level and increases CPT-1 expression, thus normalizing the amount of TG in the liver in obese mice $(29,42)$. Consistent with the findings of these previous studies, our results indicated that a high dose of AM251 inhibited CB1R protein expression and the mRNA levels of CPT-1 and citrate synthase in the livers of HFD-fed mice, despite no statistically significant change in the CB1R mRNA level of the HFD-fed mice in the presence or absence of AM251. Mitochondria are considered the primary quantitative source of free radicals in mammalian liver. However, ROS can attack polyunsaturated FA and initiate lipid peroxidation within the cells, which results in the formation of aldehyde byproducts, such as 4-hydroxy-2-nonenal (HNE) and MDA (43). Previous studies have indicated that patients with NASH have impaired liver ATP homeostasis (44), which severely depletes mtDNA, and affects mitochondrial function (10). Conversely, increased levels of antioxidants may play a protective role against the development of hepatic steatosis $(45,46)$. A master regulator of mitochondrial biogenesis and function is the transcriptional co-activator, PGC-1 $\alpha$, which coordinates the transcriptional activity of several nuclear transcription factors, such as NRF-1 and NRF-2, and transactivates TFAM, whereas decreased mitochondrial biogenesis has been observed in fatty liver $(47,48)$. PGC-1 $\alpha$ also regulates the induction of antioxidant defenses including SODs, catalase and glutathione peroxidase (49). In this study, we observed that the hepatic MDA level was significantly increased in experimental fatty liver, indicating increased oxidative stress; however, the defense against free radical-mediated injury includes deactivating antioxidative capacity. By contrast, HFD-fed mice treated with AM251 exhibited a substantial increase in the levels of hepatic SOD, 
A
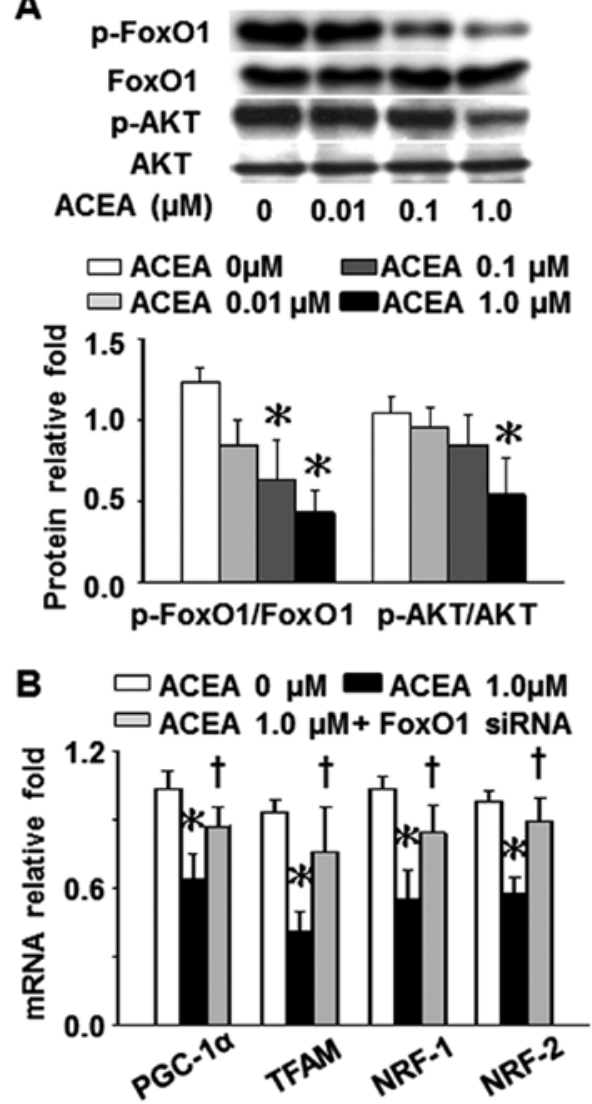
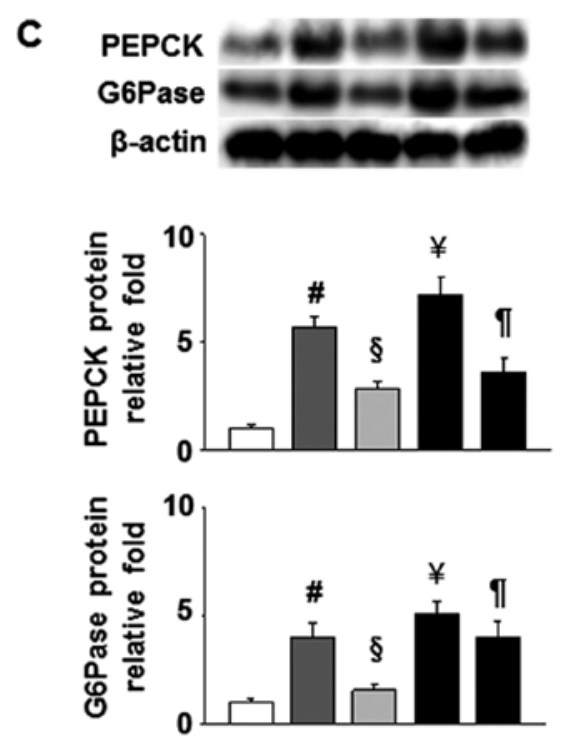

Fox01

SIRNA

ACEA

$(1.0 \mu \mathrm{M})$

CAMPIDex - + + + +

Insulin $\left(10^{-7} \mathrm{M}\right)-\quad+++$

Figure 7. Genetic ablation of forkhead box O1 (FoxO1) attenuates the ACEA-induced suppression of mitochondrial biogenesis and the ACEA-induced inhibition of the insulin-induced suppression of phosphoenolpyruvate carboxykinase (PEPCK) and G6Pase levels in AML12 cells. (A) Total and phosphorylated (p-) protein levels of FoxO1 and AKT in AML12 cells challenged with $0.01,0.1$ and $1.0 \mu \mathrm{M}$ of ACEA for $12 \mathrm{~h}$ detected by western blot analysis. (B) The mRNA levels of peroxisome proliferator-activated receptor $\gamma$ coactivator-1 $\alpha$ (PGC-1 $\alpha$ ), mitochondrial transcription factor A (TFAM), nuclear respiratory factor-1 (NRF-1) and NRF-2 were analyzed by RT-qPCR after FoxO1 gene ablation followed by exposure to $1.0 \mu \mathrm{M}$ ACEA for $12 \mathrm{~h}$. (C) Protein levels of PEPCK and G6Psase in AML12 cells after sequential treatments with FoxO1 siRNA, $1.0 \mu \mathrm{M}$ ACEA for $24 \mathrm{~h}, 10^{-7} \mathrm{M}$ insulin for $30 \mathrm{~min}$, and c-AMP/dexamethasone (c-AMP/Dex) for $2 \mathrm{~h}$, and compared to corresponding controls. Results are expressed as the means \pm SEM for 3 independent experiments. ${ }^{*} \mathrm{P}<0.05$ vs. $0 \mu \mathrm{M}$ ACEA; ${ }^{\dagger} \mathrm{P}<0.05$ vs. $1.0 \mu \mathrm{M}$ ACEA; ${ }^{*} \mathrm{P}<0.05$ vs. white bar; ${ }^{\S} \mathrm{P}<0.05$ vs. dark gray bar; ${ }^{ } \mathrm{P}<0.05$ vs. ACEA(-) + insulin + cAMP/Dex; ${ }^{9} \mathrm{P}<0.05$ vs. ACEA + insulin + cAMP/Dex.

GSH and GST, although the hepatic mRNA levels of PGC-1 $\alpha$ and NRF-2 were not markedly reduced in the HFD-fed mice. Thus, the CB1R antagonist may act as an antioxidant; a study involving ethanol-treated rats described similar findings (50). In our study, the amount of mtDNA and ATP activity in the livers of the HFD-fed mice did not noticeably decrease compared with the STD-fed control mice, which may suggest that our mouse model of DIO had only simple fatty liver.

Fasting hyperglycemia is commonly observed in patients with T2D and metabolic syndrome, indicated by a reduced glucose uptake caused by peripheral tissues and the increased production of glucose caused by hepatocytes resistant to insulin $(51,52)$. A previous study reported that the functional inhibition of FoxO1 reduced hepatic gluconeogenic activity (PEPCK and G6Pase) and improved fasting glycemia in diabetic mice (19). However, to the best of our knowledge, the mechanisms through which CB1R overexpression leads to FoxO1-mediated insulin resistance in obesity have not been explored to date. The present study demonstrated that the administration of $5 \mathrm{mg} / \mathrm{kg}$ AM251 suppressed FoxO1 activity and enhanced the phosphorylation of insulin signaling cascades, consisting of IRS-2, PI3K and AKT, in the fatty livers of HFD-fed mice, in response to the suppressed hepatic protein levels of PEPCK and G6Pase. A recent study suggested that endocannabinoids interact with hepatic CB1R to promote hepatocyte proliferation in hepatocellular carcinoma via FoxM1 and proposed an association between endocannabinoid/ CB1R system and forkhead box (Fox) transcription factors (53). Herein, by silencing the FoxO1 gene using siRNA, we further provided in vitro evidence to demonstrate that hepatic CB1R contributes to FA-induced mitochondrial disorder and hepatic insulin resistance through FoxO1 in AML12 hepatocytes. On the other hand, it has been suggested that enzymatic abnormalities are a more effective indicator of liver insulin resistance than the HOMA IR index, and that participants with hepatic insulin resistance in the highest quartile of elevated enzymes have an increased risk of developing fatty liver (54). However, in this study, we only used the HOMA-IR index as an index of global insulin resistance, which did not completely represent hepatic insulin resistance. Drugs that interfere with cannabinoid CB1R transmission suppress food-motivated behaviors, and may be clinically useful as appetite suppressants. However, neuropsychiatric side-effects, including anxiety, depression and suicidal ideation, are topics of concern (55). In a previous study, Tam et al reported that the absence of the neurobehavioral effects of AM6545 and JD5037, novel 
peripherally-restricted CB1R antagonists, were similar to those observed with rimonabant, but indicated that few neuropsychiatric side-effects occurred in humans $(28,29)$. Additionally, 1-(2,4-dichlorophenyl)- $N$-(piperidin-1-yl)-4((pyrrolidine-1-sulfonamido)methyl)-5-(5-((4-(trifluoromethyl) phenyl)ethynyl)thiophene-2-yl)-1H-pyrazole-3-carboxamide, another potential peripherally restricted CB1R antagonist, was discovered by Taiwanese investigators and demonstrated a significant weight-loss efficacy in mice with DIO (56).

In conclusion, the findings of the present study suggest the possibility that the inhibition of the anti-insulin resistance effect of CB1R through improved mitochondrial function in hepatic steatosis may be dependent on FoxO1.

\section{Acknowledgements}

This study was supported by grants from the Ministry of Science and Technology, Taipei, Taiwan (NSC 100-2314-B075-028 to L.-T.H. and NSC 102-2320-B-182-014 to T.-Y.L.).

\section{References}

1. Anstee QM, McPherson S and Day CP: How big a problem is non-alcoholic fatty liver disease? BMJ 343: d3897, 2011.

2. Zámbó V, Simon-Szabó L, Szelényi P, Kereszturi E, Bánhegyi G and Csala M: Lipotoxicity in the liver. World J Hepatol 5: 550-557, 2013.

3. Crescenzo R, Bianco F, Falcone I, Coppola P, Liverini G and Iossa $S$ : Increased hepatic de novo lipogenesis and mitochondrial efficiency in a model of obesity induced by diets rich in fructose. Eur J Nutr 52: 537-545, 2013.

4. Begriche K, Igoudjil A, Pessayre D and Fromenty B: Mitochondrial dysfunction in NASH: causes, consequences and possible means to prevent it. Mitochondrion 6: 1-28, 2006.

5. Serviddio G, Bellanti F, Vendemiale G and Altomare E: Mitochondrial dysfunction in nonalcoholic steatohepatitis. Expert Rev Gastroenterol Hepatol 5: 233-244, 2011.

6. Mantena SK, King AL, Andringa KK, Eccleston HB and Bailey SM: Mitochondrial dysfunction and oxidative stress in the pathogenesis of alcohol- and obesity-induced fatty liver diseases. Free Radic Biol Med 44: 1259-1272, 2008.

7. Mantena SK, Vaughn DP, Andringa KK, Eccleston HB, King AL, Abrams GA, Doeller JE, Kraus DW, Darley-Usmar VM and Bailey SM: High fat diet induces dysregulation of hepatic oxygen gradients and mitochondrial function in vivo. Biochem $\mathrm{J} 417$ : 183-193, 2009.

8. Rector RS, Thyfault JP, Uptergrove GM, Morris EM, Naples SP, Borengasser SJ, Mikus CR, Laye MJ, Laughlin MH, Booth FW and Ibdah JA: Mitochondrial dysfunction precedes insulin resistance and hepatic steatosis and contributes to the natural history of non-alcoholic fatty liver disease in an obese rodent model. J Hepatol 52: 727-736, 2010.

9. Marí M, Colell A, Morales A, von Montfort C, Garcia-Ruiz C and Fernández-Checa JC: Redox control of liver function in health and disease. Antioxid Redox Signal 12: 1295-1331, 2010.

10. Pessayre D and Fromenty B: NASH: a mitochondrial disease. J Hepatol 42: 928-940, 2005.

11. Sandri M: FOXOphagy path to inducing stress resistance and cell survival. Nat Cell Biol 14: 786-788, 2012.

12. Nakae J, Kitamura T, Silver DL and Accili D: The forkhead transcription factor Foxol (Fkhr) confers insulin sensitivity onto glucose-6-phosphatase expression. J Clin Invest 108: 1359-1367, 2001.

13. Samuel VT, Choi CS, Phillips TG, Romanelli AJ, Geisler JG, Bhanot S, McKay R, Monia B, Shutter JR, Lindberg RA, et al: Targeting foxol in mice using antisense oligonucleotide improves hepatic and peripheral insulin action. Diabetes 55: 2042-2050, 2006.

14. Matsumoto M, Han S, Kitamura T and Accili D: Dual role of transcription factor FoxO1 in controlling hepatic insulin sensitivity and lipid metabolism. J Clin Invest 116: 2464-2472, 2006.
15. Nakae J, Cao Y, Oki M, Orba Y, Sawa H, Kiyonari H, Iskandar K, Suga K, Lombes M and Hayashi Y: Forkhead transcription factor FoxO1 in adipose tissue regulates energy storage and expenditure. Diabetes 57: 563-576, 2008

16. Kim JJ, Li P, Huntley J, Chang JP, Arden KC and Olefsky JM: FoxO1 haploinsufficiency protects against high-fat diet-induced insulin resistance with enhanced peroxisome proliferatoractivated receptor gamma activation in adipose tissue. Diabetes 58: 1275-1282, 2009.

17. Caro JF, Dohm LG, Pories WJ and Sinha MK: Cellular alterations in liver, skeletal muscle, and adipose tissue responsible for insulin resistance in obesity and type II diabetes. Diabetes Metab Rev 5: 665-689, 1989.

18. Wajngot A, Chandramouli V, Schumann WC, Ekberg K, Jones PK, Efendic S and Landau BR: Quantitative contributions of gluconeogenesis to glucose production during fasting in type 2 diabetes mellitus. Metabolism 50: 47-52, 2001.

19. Altomonte J, Richter A, Harbaran S, Suriawinata J, Nakae J, Thung SN, Meseck M, Accili D and Dong H: Inhibition of Foxol function is associated with improved fasting glycemia in diabetic mice. Am J Physiol Endocrinol Metab 285: E718-E728, 2003.

20. Haeusler RA, Han S and Accili D: Hepatic FoxO1 ablation exacerbates lipid abnormalities during hyperglycemia. J Biol Chem 285: 26861-26868, 2010.

21. Cheng Z, Guo S, Copps K, Dong X, Kollipara R, Rodgers JT, Depinho RA, Puigserver P and White MF: Foxol integrates insulin signaling with mitochondrial function in the liver. Nat Med 15: 1307-1311, 2009 .

22. Howlett AC, Barth F, Bonner TI, Cabral G, Casellas P, Devane WA, Felder CC, Herkenham M, Mackie K, Martin BR, et al: International Union of Pharmacology. XXVII. Classification of cannabinoid receptors. Pharmacol Rev 54: 161-202, 2002.

23. Osei-Hyiaman D, DePetrillo M, Pacher P, Liu J, Radaeva S, Bátkai S, Harvey-White J, Mackie K, Offertáler L, Wang L and Kunos G: Endocannabinoid activation at hepatic CB1 receptors stimulates fatty acid synthesis and contributes to diet-induced obesity. J Clin Invest 115: 1298-1305, 2005.

24. Osei-Hyiaman D, Liu J, Zhou L, Godlewski G, Harvey-White J, Jeong WI, Bátkai S, Marsicano G, Lutz B, Buettner C and Kunos G: Hepatic CB1 receptor is required for development of diet-induced steatosis, dyslipidemia, and insulin and leptin resistance in mice. J Clin Invest 118: 3160-3169, 2008.

25. Cinar R, Godlewski G, Liu J, Tam J, Jourdan T, Mukhopadhyay B, Harvey-White $\mathbf{J}$ and Kunos G: Hepatic cannabinoid-1 receptors mediate diet-induced insulin resistance by increasing de novo synthesis of long-chain ceramides. Hepatology 59: 143-153, 2014.

26. Chanda D, Kim YH, Kim DK, Lee MW, Lee SY, Park TS, Koo SH, Lee $\mathrm{CH}$ and Choi HS: Activation of cannabinoid receptor type 1 (Cb1r) disrupts hepatic insulin receptor signaling via cyclic AMP-response element-binding protein $\mathrm{H}$ (Crebh)-mediated induction of Lipin1 gene. J Biol Chem 287: 38041-38049, 2012.

27. Liu J, Zhou L, Xiong K, Godlewski G, Mukhopadhyay B, Tam J, Yin S, Gao P, Shan X, Pickel J, et al: Hepatic cannabinoid receptor-1 mediates diet-induced insulin resistance via inhibition of insulin signaling and clearance in mice. Gastroenterology 142: 1218-1228.e1, 2012 .

28. Tam J, Vemuri VK, Liu J, Bátkai S, Mukhopadhyay B, Godlewski G, Osei-Hyiaman D, Ohnuma S, Ambudkar SV, Pickel J, et al: Peripheral CB1 cannabinoid receptor blockade improves cardiometabolic risk in mouse models of obesity. J Clin Invest 120: 2953-2966, 2010.

29. Tam J, Cinar R, Liu J, Godlewski G, Wesley D, Jourdan T, Szanda G, Mukhopadhyay B, Chedester L, Liow JS, et al: Peripheral cannabinoid-1 receptor inverse agonism reduces obesity by reversing leptin resistance. Cell Metab 16: 167-179, 2012.

30. Tedesco L, Valerio A, Dossena M, Cardile A, Ragni M, Pagano C, Pagotto U, Carruba MO, Vettor R and Nisoli E: Cannabinoid receptor stimulation impairs mitochondrial biogenesis in mouse white adipose tissue, muscle, and liver: The role of eNOS, p38 MAPK, and AMPK pathways. Diabetes 59: 2826-2836, 2010.

31. Kohli R, Pan X, Malladi P, Wainwright MS and Whitington PF: Mitochondrial reactive oxygen species signal hepatocyte steatosis by regulating the phosphatidylinositol 3-kinase cell survival pathway. J Biol Chem 282: 21327-21336, 2007.

32. Tedesco L, Valerio A, Cervino C, Cardile A, Pagano C, Vettor R, Pasquali R, Carruba MO, Marsicano G, Lutz B, et al: Cannabinoid type 1 receptor blockade promotes mitochondrial biogenesis through endothelial nitric oxide synthase expression in white adipocytes. Diabetes 57: 2028-2036, 2008. 
33. Chen CC, Lee TY, Kwok CF, Hsu YP, Shih KC, Lin YJ and Ho LT: Major urinary protein 1 interacts with cannabinoid receptor type 1 in fatty acid-induced hepatic insulin resistance in a mouse hepatocyte model. Biochem Biophys Res Commun 15: 1063-1068, 2015.

34. Yabaluri N and Bashyam MD: Hormonal regulation of gluconeogenic gene transcription in the liver. J Biosci 35: 473-484, 2010.

35. Medina-Santillán R, López-Velázquez JA, Chávez-Tapia N, Torres-Villalobos G, Uribe M and Méndez-Sánchez N: Hepatic manifestations of metabolic syndrome. Diabetes Metab Res Rev: Mar 7, 2013 (Epub ahead of print). doi: 10.1002/dmrr.2410.

36. Lottenberg AM, Afonso MS, Lavrador MS, Machado RM and Nakandakare ER: The role of dietary fatty acids in the pathology of metabolic syndrome. J Nutr Biochem 23: 1027-1040, 2012.

37. Utzschneider KM and Kahn SE: Review: The role of insulin resistance in nonalcoholic fatty liver disease. J Clin Endocrinol Metab 91: 4753-4761, 2006.

38. Gao CL, Zhu C, Zhao YP, Chen XH, Ji CB, Zhang CM, Zhu JG, Xia ZK, Tong ML and Guo XR: Mitochondrial dysfunction is induced by high levels of glucose and free fatty acids in 3T3-L1 adipocytes. Mol Cell Endocrinol 320: 25-33, 2010.

39. Chanda D, Kim DK, Li T, Kim YH, Koo SH, Lee CH, Chiang JY and Choi HS: Cannabinoid receptor type 1 (CB1R) signaling regulates hepatic gluconeogenesis via induction of endoplasmic reticulum-bound transcription factor cAMP-responsive elementbinding protein $\mathrm{H}(\mathrm{CREBH})$ in primary hepatocytes. J Biol Chem 286: 27971-27979, 2011.

40. Ruby MA, Nomura DK, Hudak CS, Barber A, Casida JE and Krauss RM: Acute overactive endocannabinoid signaling induces glucose intolerance, hepatic steatosis, and novel cannabinoid receptor 1 responsive genes. PLoS One 6: e26415, 2011.

41. Merroun I, Sánchez-González C, Martínez R, López-Chaves C, Porres JM, Aranda P, Llopis J, Galisteo M,Zarzuelo A, Errami M and López-Jurado M: Novel effects of the cannabinoid inverse agonist AM 251 on parameters related to metabolic syndrome in obese Zucker rats. Metabolism 62: 1641-1650, 2013.

42. Jourdan T, Demizieux L, Gresti J, Djaouti L, Gaba L, Vergès B and Degrace P: Antagonism of peripheral hepatic cannabinoid receptor-1 improves liver lipid metabolism in mice: Evidence from cultured explants. Hepatology 55: 790-799, 2012.

43. Poli G and Schaur RJ: 4-Hydroxynonenal in the pathomechanisms of oxidative stress. IUBMB Life 50: 315-321, 2000.

44. Pérez-Carreras M, Del Hoyo P, Martín MA, Rubio JC, Martín A, Castellano G, Colina F, Arenas J and Solis-Herruzo JA: Defective hepatic mitochondrial respiratory chain in patients with nonalcoholic steatohepatitis. Hepatology 38: 999-1007, 2003.

45. Violi F and Cangemi R: Pioglitazone, vitamin E, or placebo for nonalcoholic steatohepatitis. N Engl J Med 363: 1185-1186, author reply 1186, 2010.
46. Lavine JE, Schwimmer JB, Van Natta ML, Molleston JP, Murray KF, Rosenthal P, Abrams SH, Scheimann AO, Sanyal AJ, Chalasani N, et al; Nonalcoholic Steatohepatitis Clinical Research Network: Effect of vitamin E or metformin for treatment of nonalcoholic fatty liver disease in children and adolescents: the TONIC randomized controlled trial. JAMA 305: 1659-1668, 2011.

47. Aharoni-Simon M, Hann-Obercyger M, Pen S, Madar Z and Tirosh O: Fatty liver is associated with impaired activity of PPAR $\gamma$-coactivator $1 \alpha(\mathrm{PGC} 1 \alpha)$ and mitochondrial biogenesis in mice. Lab Invest 91: 1018-1028, 2011.

48. Wang S, Kamat A, Pergola P, Swamy A, Tio F and Cusi K: Metabolic factors in the development of hepatic steatosis and altered mitochondrial gene expression in vivo. Metabolism 60: 1090-1099, 2011.

49. St-Pierre J, Drori S, Uldry M, Silvaggi JM, Rhee J, Jäger S, Handschin C, Zheng K, Lin J, Yang W, et al: Suppression of reactive oxygen species and neurodegeneration by the PGC-1 transcriptional coactivators. Cell 127: 397-408, 2006.

50. Tsvetanova E, Kessiova M, Alexandrova A, Petrov L, Kirkova M and Todorov S: In vivo effects of CB1 receptor ligands on lipid peroxidation and antioxidant defense systems in the rat brain of healthy and ethanol-treated rats. Pharmacol Rep 58: 876-883, 2006.

51. Klover PJ and Mooney RA: Hepatocytes: critical for glucose homeostasis. Int J Biochem Cell Biol 36: 753-758, 2004

52. Garber AJ: Obesity and type 2 diabetes: which patients are at risk? Diabetes Obes Metab 14: 399-408, 2012.

53. Mukhopadhyay B, Schuebel K, Mukhopadhyay P, Cinar R, Godlewski G, Xiong K, Mackie K, Lizak M, Yuan Q, Goldman D and Kunos G: Cannabinoid receptor 1 promotes hepatocellular carcinoma initiation and progression through multiple mechanisms. Hepatology 61: 1615-1626, 2015.

54. Sesti G, Fiorentino TV, Hribal ML, Sciacqua A and Perticone F: Association of hepatic insulin resistance indexes to nonalcoholic fatty liver disease and related biomarkers. Nutr Metab Cardiovasc Dis 23: 1182-1187, 2013.

55. Christensen R, Kristensen PK, Bartels EM, Bliddal H and Astrup A: Efficacy and safety of the weight-loss drug rimonabant: a meta-analysis of randomised trials. Lancet 370: 1706-1713, 2007.

56. Chang CP, Wu CH, Song JS, Chou MC, Wong YC, Lin Y, Yeh TK, Sadani AA, Ou MH, Chen KH, et al: Discovery of 1-(2,4dichlorophenyl)- $N$-(piperidin-1-yl)-4-((pyrrolidine-1-sulfonamido) methyl)-5-(5-((4-(trifluoromethyl)phenyl)ethynyl)thiophene-2-yl)$1 H$-pyrazole-3-carboxamide as a novel peripherally restricted cannabinoid-1 receptor antagonist with significant weight-loss efficacy in diet-induced obese mice. J Med Chem 56: 9920-9933, 2013. 